\title{
RESEARCH AND DEVELOPMENT OF LASER ENGRAVING AND MATERIAL CUTTING MACHINE FROM 3D PRINTER
}

\author{
Antonin DURNA, Jiri FRIES, Leopold HRABOVSKY, Ales SLIVA \\ VSB-Technical University of Ostrava
}

\author{
Jozef ZARNOVSKY \\ Slovak University of Agriculture in Nitra
}

\begin{abstract}
:
This article deals with the adjustment of a 3D printer for laser engraving and material cutting. The print head can be fitted with a solid laser diode module, which achieves a compact size while retaining its useful power. Two paths lead to the use of such a concept. It is possible to equip the existing print head with a module, which also brings a number of disadvantages such as, for example, the reduction of the printing space or the need for a suitable mounting design. A more elegant solution is to consider this in the design of a 3D printer and design a system to exchange the print heads for 3D printing and laser engraving. Such a solution allows full utilization of the workspace and simple installation of the effector for the required type of work. According to the installed power of the laser diode, it is possible not only to engrave but also cut material such as thin wood, veneer or acrylic glass. The use of such a machine is not only for graphic elements but for the creation of various stencils, boxes or simple models, which can be made up of plastic-burning pieces. The laser module is controlled by a driver, which is designed for the device. This is connected to a 3D printer control board. It is, therefore, necessary for the control board to have at least two pins, which can be controlled after adjusting the control firmware. Most laser modules are normally equipped with an adjustable lens, which is used to concentrate the focus of a laser for the given distance against the worktop. Thus, the modified 3D printer can perform its function as a multi-purpose CNC machine, while a basic platform similar for both devices is used.
\end{abstract}

Key words: 3D printer, CNC machine, engraving, laser

\section{INTRODUCTION}

Combining a 3D printer and laser for engraving is very convenient, and it brings a number of benefits. Thus, the 3D printer becomes a complex machine, enabling easy prototyping not only functional printed but also design elements. With the help of a laser, it is possible to burn thin acrylic glass, which can serve as a building element of various structures and as part of the design. For example, various boxes for electronics are commonly produced from such material. With a suitable adjustment, various graphic elements can be made into a material surface. Similarly, it is also very easy to graphically modify the surface of the veneer. Such material can be also cut with a laser, both for creating graphic elements and various precise face stencils. Another important option in the prototyping industry is the creation of printed circuit boards. The surface of the copper-plated cuprextit plate can be adjusted with a thin varnish which is then burned by laser and these bare spots can be etched. The remaining parts of the plate protected by the varnish then act as conductive paths. The same procedure can be done using appropriate adhesive tape, which will peel off in those places to be etched $[1,11,15,18]$.
The benefit of connecting a 3D printer and a laser engraving machine is the use of one design for both purposes. This article describes the necessary design modifications to an existing 3D printer, as well as the knowledge that is important for the machine design to use the capabilities of both arrangements. As part of the adjustments during testing, the 3D printer noise measurement was performed, using two types of control drivers. These have a significant impact on the noise of the machine. The high noise level is not desirable in the case its placement in a workroom, where it can violate hygiene rules and ergonomic standards.

A 3D printer, as well as laser burner, is a compact CNC machine. Thanks to this analogy, it is possible and simple to use 3D printers as a platform for a laser. A great advantage is a possibility of steering the z-axis as well. Using this, after adjusting the laser focus, it is possible when changing the thickness of the burned material to simply move the work head in the z-axis. Conversely, the disadvantage is the size of the workspace. A regular plotter can burn into a large $x$ and $y$-axis format, while in the z-axis it can be done only in a small range, and adjustable manually or electronically. Also, there are plotters which are not equipped with the 
possibility of movement in the vertical axis and the focal length must be changed every time you change the material thickness. These are mainly intended for the processing of thin materials [5].

\section{METHODOLOGY OF RESEARCH}

In the very first place, it was necessary to decide whether the modification of an existing 3D printer will be done, or a completely new structure will be designed. In this article, an existing printer was modified. However, the documentation with relevant figures is processed to describe the development of a new universal 3D printer.

To connect the laser module correctly, it was necessary to evaluate all the requirements and select an appropriate control board. Nevertheless, the majority of boards that are available on the market meet this requirement and support the module control. Laser power is solved separately, which simplifies the selection process for an appropriate control board and connection of electronics. Only the power supply of the laser module and its control are solved here.

For precise control of the laser beam, it is essential to understand its function and characteristics from the beam formation point of view and its influence on the workpiece material, as well as from the point of electronic components view.

Laser diode life is proportional to the input current setting. In the case of an increase, it is possible to use higher power, but at the cost of reduced service life, or the danger of its total damage. Thus, it is good to adhere to the values prescribed by the manufacturer.

Noise level measurements were done in order to reduce the noise for the given design. Using the measured and recorded values for compared tested drivers, it was possible to find a proper solution. The new design uses a driver with greater micro stepping and utilizes active cooling with fans that provide less noise. This way, we can significantly affect the level of noise the printer produces.

The selection of firmware is directly dependent on the type of control board. Some of these allow to use only firmware manufactured by its producer, others are more universal. A suitable solution is to choose one that can be used with multiple boards and has the appropriate support. The ideal is the one where it is possible to switch directly between the 3D printing option and the laser burning, instead of having to reload the firmware whenever the working head changes.

There are many types of worktops for 3D printers. However, it is necessary to modify the board for the use of a laser, both for the safety in terms of a beam reflection, and the clamping of the burned part.

\section{RESULTS}

\section{Structural design}

When designing a printer and for the future consideration of the interchangeable head, it is important to take into account sufficient space for the machine work head, both for the 3D printer dosing system and for the laser module.

This is generally large depending on the installed power of the machine. A large part of the module consists of an aluminum cooler with forced cooling provided by a fan. However, the dosing mechanism in most cases will be bulkier than the laser module. The design of 3D printers is solved in such a way that the axis of the print nozzle passes through the z-axis, forming the center of the print head. The print space and print head feed size in each axis are adjusted to allow the print nozzle to move around the entire surface of the worktop (heat bed). Therefore, to exploit the potential of the workspace it is important to place the laser module axis, the one that the laser beam passes through, on the print nozzle axis, or as close to each other as possible. The design of the clamping mechanism is also substantial, where it is possible to fasten both the print mechanism as a whole or the laser module. A practical solution, for example, is to fit a unit on one part of the printing platform using the shaped contact, and in the other one can be fastened with a bolt. Thus, it is easy to replace it, as it is then a user-friendly solution allowing for plain handling, see Fig. 1,2 and 3.

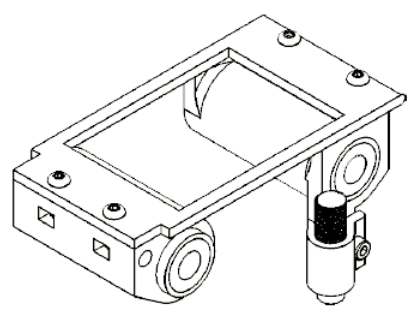

Fig. 1 Interchangeable head

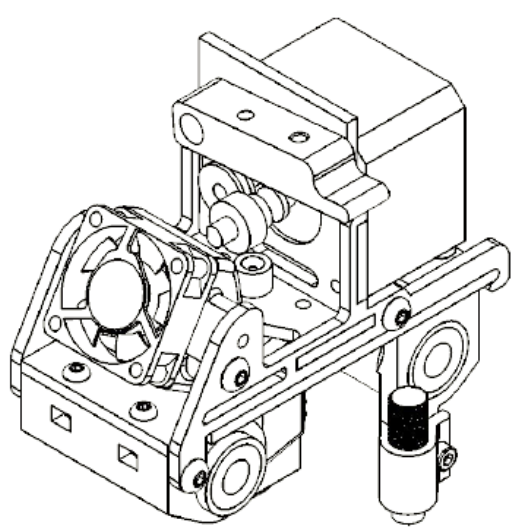

Fig. 2 Interchangeable head for 3D printing

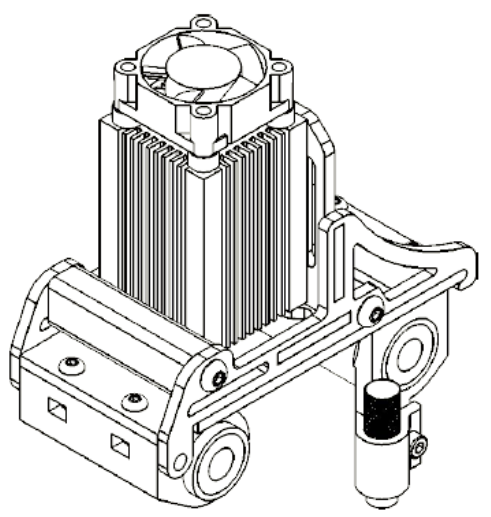

Fig. 3 Interchangeable head for laser engraving

Another option is to attach the laser module to a 3D printer, which is not, however, designed for it, and is essentially upgraded by a laser module. With this option, you will most likely not be able to position the laser axis on the print nozzle axis, but outside it. Therefore, the working space will be considerably limited, Fig. 4. 


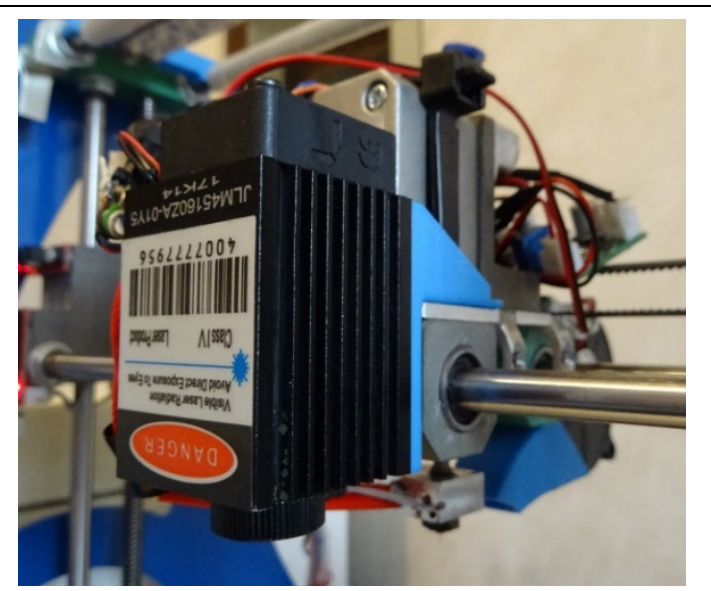

Fig. 4 Laser module mounted on a 3D printer and an extruder

\section{Connection and control}

The laser module is connected with the driver. In Fig. 5 is a laser module connected to driver.

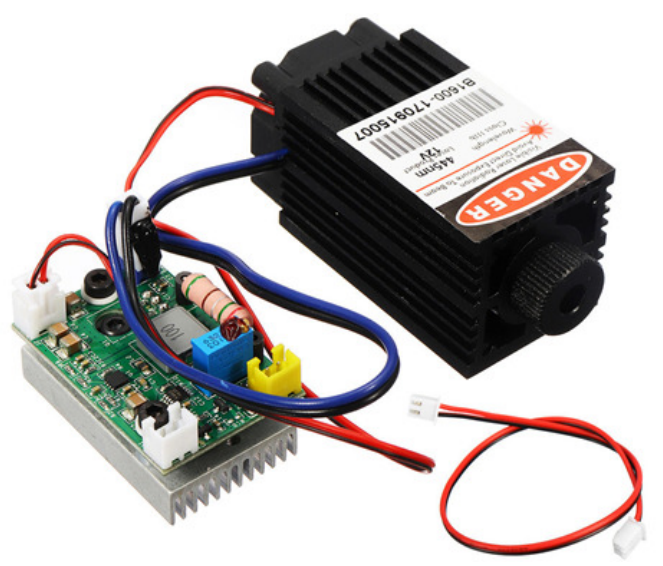

Fig. 5 Laser module with cooler and laser driver Source: [2].

On it, it is possible to set the current value that flows into the laser diode. It also powers the cooling of the module. The driver itself is connected to the power supply and to the TTL control (transistor-transistor-logic).

Transistor-transistor-logic is a control unit, in which to the logical 0 a voltage of $0 \mathrm{~V}$ is assigned, and to the logical 1 the voltage of $5 \mathrm{~V}$. The logic turns the laser diode on and off and, as necessary, controls the burning process [7].

In addition, PWM (Pulse Width Modulation) can be used for control, which is a modulation for analogue signal transmission using a two-value signal. As a two-value variable, the voltage and current are used. The signal is transmitted using alternating, which means switching the module on/off in a certain ratio $[4,8]$.

Thanks to PWM it is possible to regulate laser power, and that way, in addition to cutting, it allows us to use laser for engraving black and white shapes into wood. By changing the power, it is possible to change the depth of the burn and thus change the color shade of the burnt place [12]. In Fig. 6 is a simple laser driver, which is sufficient to control the laser module to a power of approximately $1.6 \mathrm{~W}$. Higher power may not be enough to transfer larger currents and the unit overheats considerably. Therefore, it is advisable to use active cooling or a more powerful driver [20].

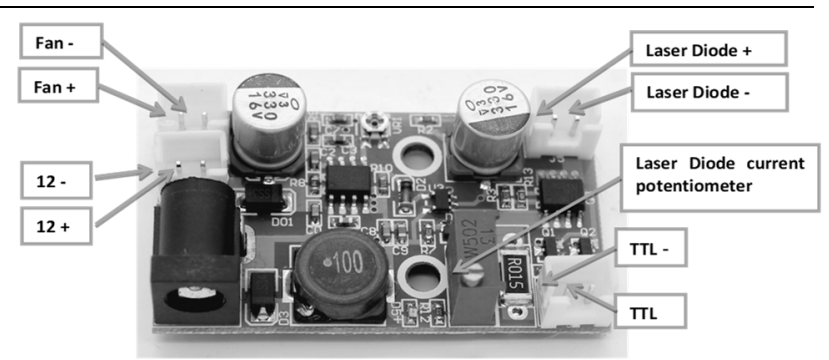

Fig. 6 The laser connecting to the control board Source: [6].

\section{Voltage-current characteristic}

Laser diodes have voltage-current characteristics like other diodes Fig. 7. A significant current flows only above a certain critical voltage, depending on the material used for the given diode. Above the critical voltage, the current grows rapidly along with the voltage. Laser diodes are not operated normally using a fixed voltage, as the current could very sensitively depend on this voltage and could also be substantially influenced by the temperature of this device. It could even cause its damage: a high current could lead to a strong rise in temperature and eventually destroy the diode.

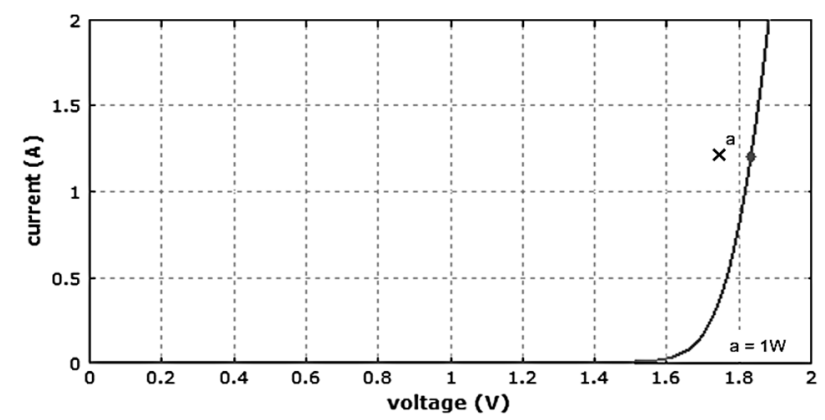

Fig. 7 Voltage-current characteristics of the laser diode with power $1 \mathrm{~W}$ and wavelength $808 \mathrm{~nm}$. At $1 \mathrm{~W}$ power, the current is about $1.2 \mathrm{~A}$ and the voltage is $1.82 \mathrm{~V}$ Source: [6].

That is why, in practice, a laser diode driver is usually used to stabilize a certain current. This means that the voltage is automatically adjusted so that the desired current is obtained. Alternatively, the constant power mode is used, where the driving current is automatically set to achieve the desired output power.

Diode lasers can achieve high efficiency - usually in orders of $50 \%$, sometimes even above $60 \%$. The efficiency is usually limited by factors such as electrical resistance, dispersion, absorption and spontaneous emissions. Particularly high efficiency is achieved with laser diodes emitting e.g. approximately $940-980 \mathrm{~nm}$, while $808 \mathrm{~nm}$ diodes are somewhat less effective [19].

\section{Service life}

If the diode lasers are operated under conditions specified by the manufacturer, they can be very reliable and have a lifespan of tens of thousands of hours. Significantly shorter service life can be caused by a number of factors. Such factors can be operation at excessively high temperatures caused by insufficient cooling and current or voltage peaks, for example, form electrostatic discharge or from poorly designed laser driver. 
To increase their service life, laser diodes are often operated at reduced current levels, thus at the output power [6, 13].

\section{Machine noise}

The noise level of a 3D printer is influenced by the type of stepping motor drivers and the noise of a cooling fan used. Theoretically, the noise level of a 3D printer and a printer with a laser module should be comparable, however, the speed of the work head movement varies. While 3D printing uses higher speeds, and therefore more noise is generated due to the higher speed of the stepping motors, for laser burning these speeds are significantly lower. The same fan that is used for cooling the print head extruder is also used for cooling the laser module. A stepping motor used to drive extruder, if not geared, operates at relatively small speeds, and thus its noise level is minimal [14]. The only difference is that the cooling of the printer part is used during the 3D printing. This fan runs as needed when printing, and therefore, it is also one of the sources of noise. For this reason, the machine for engraving is quieter. It is also essential whether it is a 3D printer with a closed working space that slightly dampens that noise, or the one with an open working place, which fails to fulfil this function. Measurement was done in a closed room. The printer was placed on one side approximately $30 \mathrm{~cm}$ from the wall Fig. 8. The noise level in the room at standstill reached $36.0 \mathrm{~dB}$ which corresponds to a quiet room. The device used for this measuring was TES1350A.

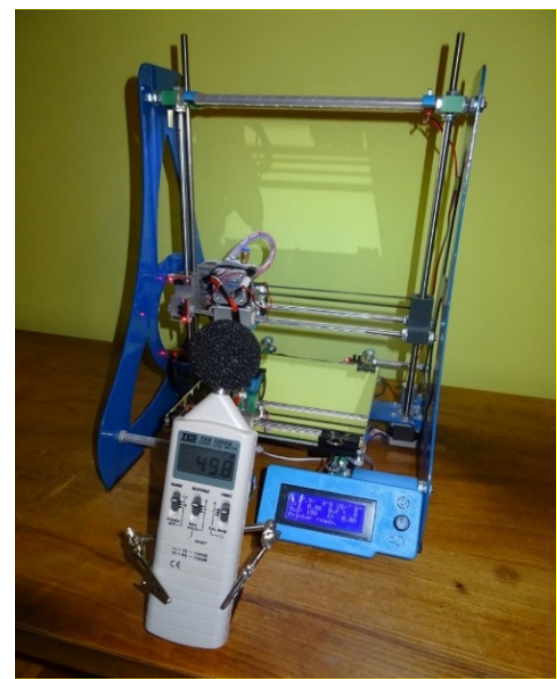

Fig. 8 3D printer noise level measurement

For each measurement, the same component was used with the same setting parameters for both tested software. The main objective of the measurement was to compare the noise level generated during normal operation (when printing) using two types of stepping motor drivers. Namely, DRV8825 driver with microstepping $1 / 32$, normally used for 3D printers and TMC2208 driver with microstepping 1/256, Table 1 and Table 2.

Table 1 Measured values of the noise level when changing the driver

\begin{tabular}{lcc}
\hline & DRV8825 & TMC2208 \\
\hline Repetier-Host & $72.3 \mathrm{~dB}$ & $66.4 \mathrm{~dB}$ \\
Simplify 3D & $72.1 \mathrm{~dB}$ & $65.7 \mathrm{~dB}$ \\
\hline
\end{tabular}

Table 2

Measured values of the noise level when changing bearings

\begin{tabular}{lcc}
\hline & Slide bearings & Rolling bearings \\
\hline Repetier-Host & $66.4 \mathrm{~dB}$ & $68.3 \mathrm{~dB}$ \\
Simplify 3D & $65.7 \mathrm{~dB}$ & $69.2 \mathrm{~dB}$ \\
\hline
\end{tabular}

A large part of the noise when only the printer is running is caused by electronics and by its extruder fan. The noise level reached $49.9 \mathrm{~dB}$. The ventilator of the electronics can be replaced by a fan with modified blades to obtain a lower noise level. In addition, the source is equipped with active cooling, where the fan is put into operation according to the source load, which also creates a sizeable share of noise.

This measurement was done in a closed room.

The difference in the measured values was also caused by the software used to generate G-code, probably caused by different excitations for engines. The more current equals to the more noise. S3D is a more friendly software in a certain way, and with the same settings as Repetier-Host, its printing time is shorter. In any case, Repetier-Host creates more accurate and quality printed parts.

The noticeable difference in noise level also considers the bearings used for these solutions. Slide bearings do not contain any rolling elements that could create noise during their linear moving along the bars.

It should be noted that the shape of the noise level curve is not linear, but logarithmic, therefore, the increase of noise level by $3 \mathrm{~dB}$ means the increase of two-fold performance. Form the measurement results it is quite clear that the stepping motors drivers with micro stepping can significantly reduce the noise level of the entire machine. This is due to a smoother transition of the engine steps when rotating. The slight difference also consists of the used linear bearings. However, each implementation has its advantage and disadvantages concerning the maintenance, assembly, and other properties.

\section{D Printer firmware settings}

Connection to the printer motherboard is important. This should allow the output to two free pins that can be controlled. The laser driver is connected to these pins. It is also necessary to adjust the control firmware so that when the $\mathrm{G}$-Code is recorded that contains the command to run the laser, the 3D printer transmits the signal to the driver. The majority of home-built printers and even some delivered by manufacturers allow you to modify the firmware.

\section{Worktop adjustment}

For 3D printing, the worktop is the so-called HeatBed. This is mainly a cuprextit plate with an etched pattern that serves as a resistance heating. Other designs such as aluminum plate are also used, with an adhesive heating foil attached on the bottom side. The heating of the print mat is important and allows the printing of materials that have greater thermal expansion and contractility [9].

This helps keep the printed part on the mat and the workpiece does not peel or crack. The upper part is equipped with a glass and an agent, allowing sufficient adhesion to keep the printed part on the mat. In addition to glass, steel plates are used very often, fixed on the mat using a magnet. 
For engraving, it is sufficient to use a mat that can be exchanged for glass or steel plate. Ideally, it can be made of wood e.g. beech plywood is suitable here. This is mainly for safety reasons. In the event that the beam accidentally worked outside the engraved surface, it would not be reflected and cause damage to the operator's eyes. Even so, it is very important to use safety goggles when working with the laser. Moreover, the wooden mat is not expensive. When the laser crosses over it, it will slightly damage the wooden plate, which will inappreciably reduce its usability. Material for burning can be fixed using double-sided tape, or, in the case of a heavier workpiece, it is sufficient enough to place it at a specified location in the working area. As there is no high feed rate of the working axes during engraving, there are no shocks that could shift the component away. The most suitable solution is to create a system of holes in the wooden board, where the burned component can be clamped directly, or place breakpoints into these holes to prevent movement of a workpiece. If the burning pad is somehow secured for the 3D printer workbench, it can be done using e.g. a shape contact. Thus, when reassembling and dismantling, its position could be changed easily. It is convenient to burn the coordinate network directly into the working pad, which will help you to position the workpiece correctly during the work $[3,10,16,17]$.

\section{DISCUSSION}

It should be noted that when the laser burns a plastic workpiece, there is a considerable amount of fumes forming. Thus, it is important to place the machine in a well-ventilated room. When burning wooden pieces, smoke is produced, as wood burns. This also results in the additional fly ash forming that clings to the structure of the printer. If the 3D printer is equipped with slide bearings, it is important to count with the increased dustiness. Should the entire structure be placed in a closed box in order to maintain a steady temperature for $3 d$ printing, an extractor must be used for laser burning to ensure that the fumes and flue gases are drawn off.

There are a number of different drivers available on the market to control the stepper motor. The drivers that were used for comparison are only examples of the older series DRV8825 and later TMC2208 that are used nowadays. However, between the TMC2208 series and even more recent types there are no longer such significant differences in noise. Their advantage is mainly more accurate stepping and smoother running.

\section{CONCLUSION}

When designing it is important to consider the weight of the print head. This will be larger than for a head that does not allow for its replacement. It is therefore advisable to take this knowledge into account in the further design of the machine, especially concerning the frame stiffness. When burning, however, no high speeds are used, compared to 3D printing. Therefore, there are no shocks due to dynamic forces. Weight gain will only be noticeable on the print head. If the laser module is installed, we must only adjust the laser focus, which is very simple. It is important to use protective goggles otherwise you may experience eye damage. It is equally important that the machine is operated in a well-ventilated room or a smoke extraction must be used. During the burning process, a slight amount of smoke is produced from the wood used, but hazardous harmful fumes may also be produced when processing plastics. A device designed with a work head replacement system enables not only 3D printing but also laser engraving. Likewise, it is also possible to design another working head later, e.g. for printing with multiple nozzles. Such a machine achieves a certain universality, while the design of the originally intended machine is not particularly impaired. The possible production of components using acrylate glass or printed circuit boards increases the productivity of prototyping.

\section{ACKNOWLEDGEMENTS}

This article has been written in connection with the project The Research and Innovation of Modern Technologies in Manufacturing Practice, reg. no. SP2019/2 supported by Specific Research program financed by the Ministry of Education, Youth and Sports and the project Support for Science and Research in the Moravian-Silesian Region 2017 (RRC/10/2017) - reg. no. MK9347014.

\section{REFERENCES}

[1] Durna, A., Fries, J. 3D Printer With Replacement Head For Engraving Printed Circuit Boards. In SGEM 2017, Albena, Bulgaria. Volume 17. Issue 62. Sofia: STEF92 Technology Ltd., 2017, 877-884 pp. DOI: $10.5593 /$ sgem2017/62/S27.112.

[2] Banggood.com, $1600 \mathrm{~mW} 445 \mathrm{~nm}$ Focusable Blue Laser Module. Banggood [online]. 2019 [cit. 2019-04-29]. Available from: https://www.banggood.com/1600mW445nm-Focusable-Blue-Laser-Module-for-DIY-Laser-Printer-Engraving-Machine-Engraver-p-232825.html?cur_warehouse $=\mathrm{CN}$.

[3] Kováč, J., Krilek, J., Kučera, M., Barcík, Š. The impact of design parameters of a horizontal wood splitter on splitting force. In Drvna industrija: znanstveni časopis za pitanja drvne technologije. ISSN 0012-6772, 2014, vol. 65, broj 4, s. 263-271.

[4] Odicforce.com, 0-2.5 A Laser Diode Driver for 405, 450, 520, 635 and $660 \mathrm{~nm}$ Diodes TTL Modulation, 12V (V2). Odic Force Lasers [online]. UNITED KINGDOM: ofl@odicforce.com, 2019 [cit. 2019-04-29]. Available from: https://odicforce.com/2A-Laser-Diode-Driver-for405-450-520-635-and-660nm-Diodes-TTL-Modulation$12 \mathrm{~V}$.

[5] Olivka, P., Mihola, M., Novak, P., Kot, T. (2016) The 3D Laser Range Finder Design for the Navigation and Mapping for the Coal Mine Robot. In $17^{\text {th }}$ IEEE International Carpathian Control Conference, ICCC 2016. 2016. pp. 533-538.

[6] [6] Paschotta, Dr. Rüdiger. Laser Diodes. RP Photonics Encyclopedia [online]. Germany, 2019 [cit. 2019-04-30]. Available from: https://www.rp-photonics.com/laser_diodes.html.

[7] Reichel, J. a M. Encyklopedie fyziky [Physics Encyclopedia] - [online]. Praha, 2016 [cit. 2019-04-28]. Available from: http://fyzika.jreichl.com/main.article/view/1326-ttl-logika.

[8] Robodoupe.cz, Pulzně-šířková modulace. RoboDoupě [RobooDen] - [online]. 2019 [cit. 2019-04-29]. Available from: http://robodoupe.cz/2016/pulzne-sirkova- modulace/. 
[9] Sliva, A., Brazda, R., Prochazka, A., Martynkova, G. S., Barabaszova, K. C. Study of the optimum arrangement of spherical particles in containers having different cross section shapes. Journal of Nanoscience and Nanotechnology. 2019. vol 19, iss. 5, pp. 2717-2722. DOI: 10.1166/jnn.2019.15873.

[10] Žitňansky, J., Žarnovsky, J., Ružbarsky, J. Analysis of physical effects in cutting machining. In Advanced Materials Research, vol. 801, special iss., pp. 51-59 (2013).

[11] Durna, A., Fries, J. Modification of the Nozzle Assembly in a 3D Printer for Printing Materials With Higher Melting Temperatures. In SGEM 2017, Albena, Bulgaria. Volume 17. Issue 62. Sofia: STEF92 Technology Ltd., 2017, 923-930 pp. DOI: $10.5593 /$ sgem2017/62/S28.118.

[12] Kudrna, L., Fries, J., Merta, M. The Technology of Plasma Cutting on a CNC Machine. In SGEM 2017, Albena, Bulgaria. Volume 17. Issue 62. Sofia: STEF92 Technology Ltd., 2017, 949-956 pp. DOI: 10.5593/sgem2017/13/S03.120.

[13] Kotsmid, S., Kuo, C., Beno, P. Buckling Loads for Steel Tube With Flattened Ends. In: Archive of Applied Mechanics. ISSN: 0939-153. Volume 2017, DOI: 10.1007/s00419-0171224-2.

[14] Trochta, M., Folta, Z., Pavlík, J. Quality of Gear Mesh and its Effects on Transmission Error. In Proceedings of the $58^{\text {th }}$ International Conference of Machine Design Departments - ICMD 2017: September $8^{\text {th }}$ 2017, Prague, Czech Republic. Prague: Czech University of Life Sciences Prague, 2017, s. 404-407.

[15] Sadilek, M., Cep, R., Sadilkova, Z., Valicek, J., Petrkovska, L. Increasing Tool Life during Turning with a Variable Depth of Cut. Materiali in Tehnologije. Volume 47, Issue 2, pages 199-203.

\section{Antonin Durna}

VSB-Technical University of Ostrava

Faculty of Mechanical Engineering

17.listopadu 15, 70833 Ostrava-Poruba, Czech Republic e-mail; antonin.durna@vsb.cz

\section{Jiri Fries}

ORCID ID: 0000-0001-9776-6878

VSB-Technical University of Ostrava

Faculty of Mechanical Engineering

17.listopadu 15, 70833 Ostrava-Poruba, Czech Republic

e-mail: jiri.fries@vsb.cz

\section{Leopold Hrabovsky}

VSB-Technical University of Ostrava

Faculty of Mechanical Engineering

17.listopadu 15, 70833 Ostrava-Poruba, Czech Republic e-mail: leopold.hrabovsky@vsb.cz

\section{Ales Sliva}

ORCID ID: 0000-0001-6109-3616

VSB-Technical University of Ostrava

Faculty of Mechanical Engineering

17.listopadu 15, 70833 Ostrava-Poruba, Czech Republic e-mail: ales.sliva@vsb.cz

\section{Jozef Zarnovsky}

ORCID ID: 0000-0002-5591-8498

Slovak University of Agriculture in Nitra

Department of Quality and Engineering Technologies

Tr. A. Hlinku 2, 94976 Nitra, Slovak Republic
[16] Kovář, L., Novák, P. Machinery for opening and closing of steelmaking furnances tap holes. METAL $2018-27^{\text {th }}$ International Conference on Metallurgy and Materials, Conference Proceedings, pp. 143-148. 2018 Tanger Ltd., Ostrava. Publisher: Tanger Ltd.

[17] Kováŕ, L. Main design characteristics of lances for steelmaking furnaces. METAL 2017 - 26th International Conference on Metallurgy and Materials, Conference Proceedings, 2017-January, pp. 176-181. 2017 Tanger Ltd., Ostrava. Publisher: Tanger Ltd.

[18] Pagáč, M., Hajnyš, J., Petrů, J., Zlámal, T., Šofer, M. The Study of Mechanical Properties Stainless Steel 316L After Production from Metal Powder with Using Additive Technology and by Method Selective Laser Melting. METAL 2017: $26^{\text {th }}$ Anniversary International Conference on Metallurgy and Materials, 2017.

[19] Vytisk, T., Janalik, R. Experimental determination of technical parameters in order to optimize the operation of a generator achieving electrical output. Proceedings of the $201516^{\text {th }}$ International Scientific Conference on Electric Power Engineering, EPE 201516 July 2015, Article number 7161182, Pages 572-574. DOI: 10.1109/EPE.2015.7161182..

[20] Honus, S., Juchelkova, D. Mathematical models of combustion, convection and heat transfer in experimental thermic device and verification. Tehnicki Vjesnik, Osijek. Volume 21, 2014, Pages 115-122. 